\title{
EDITORIAL
}

\section{LA CONSTRUCCION DE LA DEMOCRACIA EN EL SALVADOR}

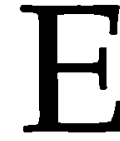

$n$ el caso de El Salvador, y en general en el resto de países de América Latina, el principio ético, sin el cual no hay democracia, es la tendencia hacia la democratización social y económica.

En el actual debate político, el discurso sobre la democracia por parte de la derecha y de algunos sectores de la izquierda intenta desconocer el carácter de clase que contiene el ejercicio de la democracia realmente existente en nuestro país y se pretende descalificar cualquier intento que trate de vincular la lucha por la democracia a una determinada concepción de transformación del orden material. Se intenta reducir la democracia a un conjunto de reglas de juego político interpartidista, transformándose en una teoría de la gobernabilidad política.

El problema social de la vida digna o de situaciones económicas que llevan a la muerte a grandes núcleos de población, no son consideradas relevantes para caracterizar la democracia y sus reglas de juego. Esta relación directa que se establece entre democracia y gobernabilidad culmina en la descalificación de las propuestas de cambio social democrático con contenido económico y de participación social.

Si bien formalmente la democracia es un régimen político que resuelve los problemas de gobierno y de representación, el significado que esto adquiere en sociedades como la nuestra es la de irse concretizando como una forma de vida, superando el ámbito pura- 
mente político y lograda a través de relaciones de índole horizontal y de la articulación de la representación formal con la capacidad de interpelación de los actores sociales frente al sistema político.

Esto significa que, más allá de resolver los problemas propios de las transiciones que han quedado pendientes (militarismo, núcleos de la derecha autoritaria, leyes, constitución, elementos simbólicoculturales, valores antidemocráticos, etc.) del régimen anterior, la construcción de la democracia en El Salvador pasa por la total y completa desmilitarización y modernización del Estado, la ampliación permanente del sistema político en la dirección de construir una democracia participativa más allá de los parámetros de la democracia liberal, el desarrollo organizativo de la sociedad civil a través de la creación de una diversidad de movimientos sociales con capacidad propositiva y transformadora y la superación de la alta concentración de la riqueza, que acentúa la pobreza y la exclusión social.

En el primer aspecto no puede prescindirse del papel dirigente del Estado en el proceso de desarrollo, superando las tesis neoliberales que proponen su retracción y disminución. Los estudios realizados durante la década de los ochenta por diversos organismos sostienen la necesidad de mantener la centralidad del Estado, pero haciéndolo más moderno, racional, para que reorganice sus funciones y/o cree nuevas, asumiendo y preservando valores ajenos al mercado, tales como la solidaridad, la igualdad y la equidad, mientras el mercado garantiza la diferencia y el pluralismo.

En el segundo aspecto, se trata de diseñar un sistema fuerte de partidos, autónomo del Estado y de los movimientos sociales, en el interior del cual se constituya una mayoría socio-política, un bloque democrático-transformador, que asegure la democracia política y enfrente las tareas de democratización global, superando tendencias hegemonistas y promoviendo formas de concertación mediante consensos elaborados a partir de los problemas reales que enfrenta la sociedad y no de esquemas ideologizantes.

En el tercer aspecto se trata de iniciar un proceso de densificación, diversificación y fortalecimiento de actores sociales que aumenten los niveles de participación, no sólo en su dimensión simbólica, sino de resolución real de problemas, construyendo una verdadera democracia participativa. 
Con relación a la alta concentración de la riqueza, se requiere una real democratización de la riqueza nacional a través de la participación más amplia posible, sobre todo de las sectores populares, en todos los mecanismos y circuitos de las decisiones económicas, lo cual supone también una revalorización de la intervención del Estado en la redistribución de los bienes producidos por todos, una reformulación de los programas de ajuste estructural, superando la dicotomía o la oposición irreductible entre el Estado y el mercado dentro del debate sobre el desarrollo y la democracia.

En realidad, el problema central de la democracia en El Salvador es la no correspondencia que se constata entre el nivel general de "desarrollo" y la situación social de gran parte de la población. Los indicadores dan cuenta que su situación social se ha mantenido en niveles muy insuficientes y en algunos casos se ha deteriorado. En El Salvador, así como en el resto de países de América Latina, la desigualdad extrema es un rasgo singular de las sociedades latinoamericanas; acentuada extraordinariamente en el presente y proyectada peligrosamente para el futuro.

Por ello, de los aspectos que hemos apuntado más arriba, las cuestiones de la democracia y de su futuro en El Salvador son inseparables de la desigualdad: las diferencias abismales en el ingreso y la condición de vida de distintos estratos de la población; las diferencias extremas en la dotación técnica y del capital y consiguientemente en la productividad de distintas fracciones de la fuerza de trabajo; las diferenciaciones sociales, culturales y económicas entre "el mundo de los pobres" y el "mundo de los ricos".

El punto fundamental que hay que reconocer es que en El Salvador, como en el resto de los países de la región, el desarrollo capitalista y la "modernización" no han favorecido cambios positivos en las pautas de distribución de los frutos del crecimiento económico; por el contrario generaron y generan una especie de dinámica de "desigualdad". La pobreza y la "extrema pobreza" son situaciones que han legado a ser muy altas.

En vista de lo anterior, resulta inverosímil que algunas fuerzas de "izquierda" y del movimiento social progresista del país hayan caído en el juego del discurso ideológico de los sectores dominantes, que centra la cuestión de la democracia en la idea de 
"gobernabilidad", que no es más que la aplicación del antiguo concepto de control, de manejo y funcionalización del conflicto. Es decir, la aplicación de técnicas para impedir que se atente contra el sistema de dominación.

Dentro de los parámetros ideológicos de la derecha, cualquier alternativa política construida sobre la base de demandas sociales, de redistribución del ingreso y beneficios económicos, es valorada como una propuesta residual de una izquierda totalitaria sin capacidad para ponderar suficientemente los beneficios de una práctica democrática $y$, por ello, causante de una posible desestabilización del "orden" democrático.

En definitiva, se liga la construcción de una democracia social y económica como una teorización errónea, donde el cambio estructural, y por ello la revolución misma de los sistema de dominación, es desalojado del debate, señalando el fin de estas opciones así como su inviabilidad histórica. Es el fin de las ideologías y de la política entendidas como una parte de una lucha objetiva por el poder donde las clases sociales, los movimientos y partidos políticos y los actores sociales luchan por construir y direccionar el proceso histórico.

Se trata de una consideración estrictamente política de la democracia, donde se la concibe como un juego instrumental para la elección de dirigentes. Es la concepción elitista de la democracia neoliberal, que soslaya que la democracia política realmente existente ha supuesto una elevada tasa de marginalidad social y una exclusión económica que ha traído un aumento considerable de la pobreza extrema, a pesar de que las cifras macroeconómicas muestran ciertos resultados que se reflejan en tasas de crecimiento o de disminución de la inflación.

Por esta razón, sin su correlato social, económico y cultural, la democracia puede terminar por definirse como un fin y un proyecto político en sí. Incluso a limitar lo político a reglas de juego y a la convocatoria permanente de elecciones formales. Si bien la representación es importante, está lejos de ser el único índice de la voluntad soberana del pueblo.

Desde nuestra realidad histórica, es importante recuperar el planteamiento de la democracia en su dimensión estructural y estra- 
tégica y reafirmar los contenidos materiales de la misma. La democracia es válida cuando política, social, económica y culturalmente da respuesta a las grandes demandas y soluciones problemas endémicos, que en nuestro país y en el resto de la región son la pobreza, la oligarquización efectiva del poder, la concentración económica, la represión, la salud, la vivienda, la educación, entre otros.

En definitiva, construir la democracia supone satisfacer los derechos sociales e individuales, acabar con el hambre, la marginalidad, la muerte por falta de medicamentos, el analfabetismo, la desnutrición, la corrupción, etc.

El pensamiento crítico debe mantener una noción de democracia donde su contenido real siga estando en la búsqueda de la justicia social, la redistribución económica y la participación políti$\mathrm{ca}$, tratandc de superar las estructuras de atraso y subdesarrollo.

El problema de la democracia en El Salvador y en América Latina sigue siendo la definición de su para qué y el alcance de su contenido. Sin esta consideración, cualquier propuesta de desarrollo quedará confinada al fracaso social, salvo si es para garantizar el poder político de las clases dominantes a través de la sobreexplotación, marginación y coacción de las grandes mayorías de nuestro pueblo y del continente. 